\title{
The Comparison and Modeling of the Driving Factors of Urban Expansion for Thirty-Five Big Cities in the Three Regions in China
}

\author{
Tian Guangjin, ${ }^{1}$ Xu Xinliang, ${ }^{2}$ Liu Xiaojuan, ${ }^{3}$ and Kong Lingqiang ${ }^{3}$ \\ ${ }^{1}$ School of Government, Beijing Normal University, Xinwai Street, Beijing 100875, China \\ ${ }^{2}$ State Key Laboratory of Resources and Environmental Information Systems, Institute of Geographical Sciences and \\ Natural Resources Research, Chinese Academy of Sciences, No. A11, Datun Road, ChaoYang District, Beijing 100101, China \\ ${ }^{3}$ State Key Laboratory of Water Environment Simulation, School of Environment, Beijing Normal University, Xinwai Street, \\ Beijing 100875, China
}

Correspondence should be addressed to Xu Xinliang; xuxliang@yahoo.com

Received 5 June 2016; Accepted 29 August 2016

Academic Editor: Ram B. Singh

Copyright (C) 2016 Tian Guangjin et al. This is an open access article distributed under the Creative Commons Attribution License, which permits unrestricted use, distribution, and reproduction in any medium, provided the original work is properly cited.

This paper presents a national- and regional-scale urban growth model (NRUGM) of China based on panel data analysis. Through the panel analysis, population growth, road construction, salary increment per capita, and secondary industry product increment were proven to be the major driving factors for national-scale urban expansion. According to Seventh Five-Year Plan, China had been divided into three regions, Eastern China, Middle China, and Western China, by their geographic position and economic development. We studied the relationship between urban expansion and the driving factors for the three regions between 1990 and 2010 in China. The driving factors of urban expansion were different for the different regions and periods. Population growth and road construction were identified as the two major factors driving urban expansion for Eastern China. Secondary industry and economic development had become the major driving factors for urban expansion over the last twenty years in Middle China. Over the same period, for Western China, economic growth had become the major driving factor for urban expansion. Our results have significant policy implications for China. The macrocontrol of the central government should utilize different policies to adjust urban expansion in the different regions.

\section{Introduction}

Across the world, rapid urban expansion has encroached on croplands, forests, water bodies, barren land, and even villages on a large scale [1-10]. The wholesale transformation of natural ecosystems and agricultural lands has resulted in widespread environmental changes in the twenty-first century [1]. The urbanization process also affects the water, carbon, aerosol, and nitrogen cycles in the climate system. Although urban land occupies only approximately $2.4 \%$ of global landmass, it is home to more than half of the world's people [11]. In large cities, air, water, and noise pollution, traffic congestion, and high housing prices influence inhabitants' quality of life.
The Chinese urbanization process has attracted global attention [5-8]. The country has experienced an unprecedented scale and rate of urban expansion over the last four decades. In 1978, China's urbanization level was only $17 \%$, but by 2010, its urban dwellers accounted for $49.68 \%$ of the total population $[12,13]$. There were 654 cities in China in 2010. The four municipalities and twenty-seven capital cities are the major cities of China. But Dalian, Qingdao, Ningbo, and Xiamen are as important as their provincial capitals. Hence, we had added the four big cities as the objects of study (Figure 1). In 2010, the thirty-five cities had a combined population of 248 million, accounting for $19.93 \%$ of the total population. Their urban population was 147 million, 


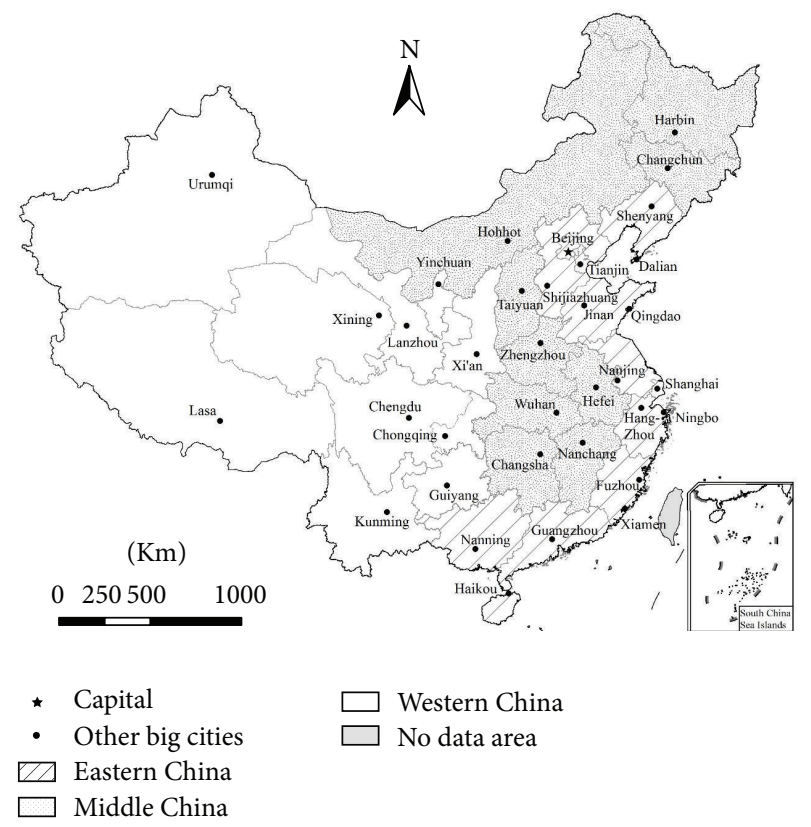

FIGURE 1: The spatial distribution of the thirty-five big cities in the three regions in China.

accounting for $38.08 \%$ of the total urban population of China [13].

Urban expansion is the spreading out of the cities and townships into the periphery areas with the urban development. A better understanding of urban expansion and its determinants is necessary to assess the impact of possible future developments on the environment, economy, and society at large [14]. The urban construction land expanded dramatically and had encroached on a great amount of arable land and threatened the grain safety of China $[6,10]$. At the same time, the urban expansion indicated the periodical difference and the regional difference in Eastern, Middle, and Western China $[6,15]$. The land use had become more intensive with economic development in Eastern China while urban land expanded remarkably in middle and western regions $[6,15]$.

Urban dynamic model can improve our understanding of the mechanisms of urban expansion. The CA (cellular automata) and ABM (agent-based model) have emerged from complexity, chaos, and cybernetics and have been widely used to simulate urban dynamics. Social and economic factors are the major factors of land use dynamics. The spatiotemporal dynamics and simulations of urban expansion of the individual cities and regions in China have been widely studied $[1,3,16-20]$. Spatial regression analysis and panel analysis have been used to simulate the urban expansion $[15,21]$.

The comparisons of urban expansion and its driving factors among the different regions in the different periods are very few. Because the economic system has transformed from the planning to market economy, the regional policies have impacted the economic growth and urban expansion. In order to speed up the economic development, the central government encouraged the coastal and Eastern China to be developed firstly after 1978. Then the big development of Western China was put forward in 2000. The comparisons of urban expansion in Eastern, Middle, and Western China and its driving factors will be beneficial to formulate the policies. The policies should promote the economic development and urban development while minimizing environmental impacts [1].

The decision-makers of the central government and local governments need to understand the factors that drive urban expansion for the different regions. However, the driving factors differ for different regions and periods. It will be beneficial, therefore, to distinguish these driving factors for policy makers. In this context, it is of great importance to build a national-scale and regional-scale urban expansion model and study its driving forces. The objectives of this study are (1) to quantify the relationships between urban expansion and its driving factors for thirty-five big cities in China and (2) to distinguish the driving factors for urban expansion among the three regions of China.

\section{Data Source and Method}

2.1. Data Source. We utilized urban land area in the thirtyfive studied cities published in the Chinese Statistics Yearbook between 1990 and 2010. We studied five periods of urban expansion for the provincial cities in China (panel $\mathrm{U}_{1}$ : 1990-2010; panel $\mathrm{U}_{2}$ : 1990-1995; panel $\mathrm{U}_{3}$ : 1995-2000; panel $\mathrm{U}_{4}$ : 2000-2005; panel $\mathrm{U}_{5}:$ 2005-2010). City-level data for eight socioeconomic variables, population increase (POPI), GDP (Gross Domestic Product) increase (GDPI), increase in investment in capital construction (IICC), salary increase per capita (SIPC), increase in roads (RI), increase in secondary industrial production (SIPI), increase in tertiary industrial production (TIPI), and increase in electricity consumption (ECI), were included. POPI indicates the impact of population growth on urban expansion. GDPI, IICC, SIPC, SIPI, and TIPI indicate the impact of economic growth. Investment in capital construction (IICC) is the investment of the new builtup reconstruction and built-up extension of the engineering of the enterprises, institutions, and administrative units. RI and ECI indicate the impact of road construction and electricity consumption. The electricity consumption indicates the energy consumption and supports the economic growth and urban expansion.

The original data of the eight indices of driving factors are extracted from the Chinese Statistics Yearbook. The units of the original data of the eight indices had been listed in Table 1. All the data was processed into the increment rate. We had listed the mean, maximum, minimum, and standard deviation of the eight indices of the thirty-five cities between 1990 and 2000 in China (Table 1).

Urban expansion is defined as a largely continuous area covered by urban facilities but may include some isolated facilities [22]. The data on urban expansion are generated by the Ministry of Housing and Urban-Rural Development (MOHURD). MOHURD is based on the actual land area that is granted the permission by the local governments to be developed in each city each year. The State Bureau of Surveying and Mapping investigated the actual increase 
TABLE 1: Statistics summary of driving factors of urban expansion in 1990-2010 in China.

\begin{tabular}{lccccc}
\hline Indices & Mean & Maximum & Minimum & $\begin{array}{c}\text { Standard } \\
\text { deviation }\end{array}$ & $\begin{array}{c}\text { Unit of the original } \\
\text { data }\end{array}$ \\
\hline Population increment, POPI & 0.0363 & 1.1179 & -0.5988 & 0.0930 & $\times 10^{4}$ people \\
GDP increment, GDPI & 0.2649 & 12.3755 & 0.0031 & 0.8213 & $\times 10^{4}$ Chinese Yuan \\
Investment increment in capital construction, IICC & 0.3161 & 11.5065 & -1.0000 & 0.6782 & $\times 10^{4}$ Chinese Yuan \\
Salary increment per capita, SIPC & 0.1773 & 5.0539 & -0.2027 & 0.2323 & Chinese Yuan \\
Road increment, RI & 0.1331 & 15.0575 & -1.0000 & 0.6301 & 0.8531 \\
Secondary industry product increment, SIPI & 0.2579 & 13.5273 & -0.1803 & $\times 10^{4}$ Chinese Yuan \\
Tertiary industry product increment, TIPI & 0.3006 & 11.6330 & -0.1599 & 0.8738 & $\times 10^{4}$ Chinese Yuan \\
Electricity consumption increment, ECI & 0.1103 & 2.3965 & -0.6664 & 0.1789 & $\times 10^{4} \mathrm{kwh}$ \\
\hline
\end{tabular}

in urban land by integrating aerial photo, remote sensing data, and ground surveys. The National Bureau of Statistics performs sample investigation and calibrates the above data. The relative error between the statistical urban land and derived total urban land area at the national was less than $2 \%$ and is considered as the best proxy of the real urban land in China [23].

\subsection{The National and Regional-Scale Urban Expansion Model} and Simulation. Urban expansion is the result of complex interactions between humans and the environment [14]. POPI, GDPI, IICC, SIPC, RI, SIPI, TIPI, and ECI are studied using the national-scale and regional-scale urban expansion model (NRUEM). Statistical techniques are well suited to investigate the relationships between these variables.

Panel data analysis is performed to study the relationships between urban expansion and its driving factors [21]. It is used to identify the major factors of urban expansion. Spatial heterogeneity and unobservable variables may cause the relation between socioeconomic variables and urban expansion. We study the relationships between urban expansion and its social and economic driving factors for each of the three regions. A model for the relationship between urban expansion and its social and economic determinants can be estimated using (1).

The panel data analysis is based on the several panels. The urban expansion model can be expressed as follows:

$$
\begin{aligned}
& \mathrm{UE}_{i t}=\alpha_{i}+\beta_{1 i} X_{1 i t}+\beta_{2 i} X_{2 i t}+\cdots+\beta_{k i} X_{k i t}+u_{i t}, \\
& \text { where } i=1,2, \ldots, N ; t=1,2, \ldots, T,
\end{aligned}
$$

where $\mathrm{UE}_{i t}$ is the urban expansion of city $i$ at the period $t$ and is the independent variable; $X_{k i t}$ is the driving factor of urban expansion for city $i$ at the period $t$ and the $k$ variable of dependent variable; $\beta_{k i}$ is a regression coefficient that is estimated for city $i$; and $u_{i t}$ is an error term.

Hausman test is used to choose the panel data model. For the model of $N$ panels, we can use (1). The testing of the sample data will decide whether it is mixed regression model, variable intercept model, and variable coefficient model. There are two hypotheses [24].

$H_{0}$ : The coefficient of variables is the same for all the panel cities. But the intercepts are different. The model is the varying intercept model.
$H_{1}$ : The coefficient of variables and intercepts were all the same for the panel cities. The model was the mixed regression model.

There are two methods of $F$ test statistics:

$$
\begin{aligned}
F_{2} & =\frac{\left(S_{3}-S_{1}\right) /[(N-1)(k+1)]}{S_{1} /[N T-N(k+1)]} \\
& \sim F[(N-1)(k+1), N T-N(k+1)], \\
F_{1} & =\frac{\left(S_{2}-S_{1}\right) /[(N-1) k]}{S_{1} /[N T-N(k+1)]} \\
& \sim F[(N-1) k, N T-N(k+1)],
\end{aligned}
$$

where $N$ is the number of panel cities; $T$ is the number of observational periods of the samples; $k$ is the number of the variables. $S_{1}, S_{2}$, and $S_{3}$ are the residual sum of squares of regression models of varying coefficient model, varying intercept model and the mixed regression model.

We test the hypothesis $H_{1}$ firstly. If $F_{2}$ is less than the threshold value of $F$ distribution, we cannot refuse the hypothesis $H_{1}$ and do not need to check the hypothesis $H_{0}$. Then mixed regression model is used to simulate the sample data. Otherwise, we should refuse the hypothesis $H_{1}$ and continue to test the hypothesis $H_{0}$. If $F_{1}$ is less than the threshold value of $F$ distribution, we cannot refuse the hypothesis $H_{0}$. Then the variable intercept model is used to simulate the sample data. Otherwise, we can refuse the hypothesis $H_{0}$. Then the variable intercept and variable coefficient model as (1) can be used to simulate the sample data. Therefore, we use the Hausman test to decide if we use the mixed regression model, variable intercept model, and variable coefficient and intercept model.

We used Eviews 6.0 to calculate the coefficient $\beta_{k i}$. Compared with time-series data model and cross-sectional data model, panel data model can avoid fluctuations over time. Therefore, the regression results are more effective.

According to the gradient development theory, the economic development will transfer to the low technological region from the high technological region. In order to speed up the economic development and improve the economic efficiency, the central government of China had put forward the three regions division in Seventh Five-Year Plan (19861990). By the combination of economic development and 
TABLE 2: Urban expansion rate of Eastern China, Middle China, and Western China (\%).

\begin{tabular}{lccc}
\hline Panel & $\begin{array}{c}\text { Eastern } \\
\text { China }\end{array}$ & Middle China & Western China \\
\hline 1990-2010 (panel $\left.U_{1}\right)$ & 688.68 & 149.82 & 265.37 \\
1990-1995 (panel $\left.U_{2}\right)$ & 193.73 & 22.51 & 22.51 \\
1995-2000 (panel $\left.U_{3}\right)$ & 23.90 & 15.93 & 34.47 \\
2000-2005 (panel $\left.U_{4}\right)$ & 73.00 & 45.90 & 44.76 \\
2005-2010 (panel $\left.U_{5}\right)$ & 25.25 & 53.13 & 45.43 \\
\hline
\end{tabular}

geographic position, China had been divided into three regions, Eastern China (Liaoning, Beijing, Tianjin, Shanghai, Hebei, Shandong, Jiangsu, Zhejiang, Fujian, Guangdong, Guangxi, and Hainan), Middle China (Heilongjiang, Jilin, Shanxi, Inner Mongolia, Anhui, Henan, Hubei, Hunan, and Jiangxi), and Western China (Sichuan, Chongqing, Yunnan, Guizhou, Tibet, Shaanxi, Gansu, Qinghai, Ningxia, and Xinjiang) (Figure 1). Shanghai, Beijing, and Guangzhou are the key economic centers in China. Shanghai is the central city of the Yangtze River Delta urban clusters. Guangzhou is the central city of the Pearl River Delta urban clusters. Beijing and Tianjin are the central cities of the surrounding Bohai Bay urban clusters. There are apparent differences between the three regions. Comparison of the differences between the three regions will help the central government to formulate the sustainable development policies, especially the urbanization policies.

We had calculated urban expansion rate of Eastern China, Middle China, and Western China for panel $U_{1}$ (19902010), panel $U_{2}$ (1990-1995), panel $U_{3}$ (1995-2000), panel $U_{4}$ (2000-2005), and panel $U_{5}(2005-2010)$ in China (Table 2). We had calculated the coefficient $\beta_{k i}$ for urban expansion and driving factors for panel $U_{1}$, panel $U_{2}$, panel $U_{3}$, panel $U_{4}$, and panel $U_{5}$ in China (Table 3). Then we calculated the coefficient $\beta_{k i}$ for urban expansion and driving factors for panels $\mathrm{U}_{1}, \mathrm{U}_{2}, \mathrm{U}_{3}, \mathrm{U}_{4}$, and $\mathrm{U}_{5}$ in Eastern China (Table 4), Middle China (Table 5), and Western China (Table 6).

2.3. The Hausman Test of Eastern China. For Eastern China, we have calculated the coefficients of the variables using Eviews 6.0 (Table 4). For the panel $\mathrm{U}_{1}$ (1990-2010), urban expansion was positively correlated with population increment (POPI) and road increment (RI). The urban expansion model can be expressed as follows:

$$
\begin{aligned}
& \mathrm{UE}_{i t}=\alpha_{i}+0.2472 \mathrm{POPI}_{1 i t}+0.2033 \mathrm{RI} X_{2 i t}+u_{i t}, \\
& \text { where } i=1,2, \ldots, N ; t=1,2, \ldots, T .
\end{aligned}
$$

At the same time, $S_{1}, S_{2}$, and $S_{3}$ are the residual sum of squares of regression models of varying coefficient model, varying intercept model, and the mixed regression model. We can get $S_{1}, S_{2}$, and $S_{3}$ values using the Eviews 6.0 software as follows:

$$
\begin{aligned}
& S_{1}=0.127548, \\
& S_{2}=0.136924, \\
& S_{2}=0.137475 .
\end{aligned}
$$

We can calculate $F_{2}$ using (2) and $F_{2}=0.1019$.
We can calculate $F_{1}$ using (3) and $F_{1}=0.1083$.

For Eastern China, the urban expansion data are between 1991 and 2010; hence, $T=20$. There are 15 cities and $N=15$. There are 8 variables, and $k=8$.

According to (2), for the 5\% level of test, $F_{2} \sim F[(N-1)$ $(k+1), N T-N(k+1)] \sim F[0.95,126,165]=1.3141$.

According to (3), for the $5 \%$ level of test, $F_{1} \sim F[(N-1) k$, $N T-N(k+1)] \sim F[0.95,112,120]=1.3579$.

Because $F_{2}$ is less than the threshold value, then we cannot refuse the hypothesis $H_{0}$. The model is the varying intercept model. The coefficient of variables is the same for all the panel cities. But the intercepts are different. The model is the varying intercept model.

We used Eviews 6.0 to calculate the coefficient $\beta_{k i}$. Compared with time-series data model and cross-sectional data model, panel data model can avoid fluctuations over time. Therefore, the regression results are more effective.

\section{Results}

3.1. The Urban Expansion of the Studied Cities. Over twenty years, the urban land area of the thirty-five provincial capitals in China expanded by $8917 \mathrm{~km}^{2}$ or $222.19 \%$. Urban expansion was faster in Eastern China and Western China and comparatively slow in Middle China (Table 2). This regional pattern can be observed in other studies. For example, Eastern China and Western China expanded more dramatically than Middle China from 1989 to 2000 [15]. For Eastern China, rapid economic development stimulated urban expansion. For Western China, the "Great Western Development Policy" stimulated investment and infrastructure construction. However, the primary grain-producing land is located in Middle China. The cropland protection policy constrains urban expansion in that region. Hence, urban expansion in Middle China was slow.

For the cities of Eastern China, urban land expanded the most dramatically from 2000 to 2005 (period $\mathrm{U}_{4}$ ) (Figure 1). The urban land of the cities in Middle and Western China expanded dramatically in periods $U_{4}$ and $U_{5}(2000-2010)$. For period $\mathrm{U}_{4}$, urban land expanded most dramatically in Eastern China, then Middle and Western China. For period $\mathrm{U}_{5}$, urban land expanded dramatically in Middle, Western, and Eastern China (Table 2).

More than $60 \%$ of the studied cities (including Beijing, Fuzhou, Xiamen, Guangzhou, Guiyang, Haikou, Hangzhou, Hefei, Harbin, Hohhot, Jinan, Qingdao, Nanjing, Nanning, Shenyang, Dalian, Shijiazhuang, Taiyuan, Tianjin, Yinchuan, and Zhengzhou) expanded the most dramatically in period $\mathrm{U}_{4}$ (2000-2005). Approximately $68 \%$ of these cities are located in Eastern China and 22\% in Middle China. In Western China, only Yinchuan and Guiyang had the highest expansion rates in period $\mathrm{U}_{4}$. During this period, the rapid urban development of China resulted in the wasteful use of land. After that, the central government implemented a strict land use policy in cities [7, 8]. In October 2008, the General Planning Outline of National Land Use (2006-2020) was issued. The measures in the planning outline slowed urban expansion in Eastern China, as urban expansion was 
TABLE 3: Urban expansion and driving factors in 1990-2010 in China.

\begin{tabular}{|c|c|c|c|c|c|}
\hline Item & $\begin{array}{c}\mathrm{U}_{1} \\
(1990-2010)\end{array}$ & $\begin{array}{c}\mathrm{U}_{2} \\
(1990-1995)\end{array}$ & $\begin{array}{c}\mathrm{U}_{3} \\
(1995-2000)\end{array}$ & $\begin{array}{c}\mathrm{U}_{4} \\
(2000-2005)\end{array}$ & $\begin{array}{c}\mathrm{U}_{5} \\
(2005-2010)\end{array}$ \\
\hline Population increment, POPI & $0.2038^{* * *}$ & $0.3304^{* * *}$ & $0.0782^{* * *}$ & 0.0752 & -0.0616 \\
\hline GDP increment, GDPI & 0.0841 & $0.0838^{* * *}$ & $0.7161^{* * *}$ & 0.0091 & 0.0047 \\
\hline Investment increment in capital construction, IICC & -0.0005 & -0.0002 & -0.0015 & $0.0401^{* * *}$ & $0.0428^{* * *}$ \\
\hline Salary increment per capita, SIPC & $0.1070^{* *}$ & -0.0169 & $0.0300^{* *}$ & 0.0682 & 0.0344 \\
\hline Road increment, RI & $0.0401^{* *}$ & -0.0017 & 0.0109 & $0.2095^{* * *}$ & -0.0197 \\
\hline Secondary industry product increment, SIPI & $0.0982^{* *}$ & 0.0046 & 0.4138 & $0.2881^{* * *}$ & $0.0846^{*}$ \\
\hline Tertiary industry product increment, TIPI & -0.0219 & $0.0511^{* *}$ & 0.2764 & -0.039 & -0.01 \\
\hline Electricity consumption increment, ECI & 0.0135 & $0.0791^{* * *}$ & $0.0300^{* * *}$ & $0.0224^{* *}$ & $0.0202^{* * *}$ \\
\hline Constant & 0.0860 & 0.0647 & 0.0514 & 0.0346 & 0.0546 \\
\hline Durbin-Watson stat & 1.9037 & 2.0378 & 2.6353 & 2.3684 & 2.2333 \\
\hline$R$-squared & 0.6341 & 0.5946 & 0.511 & 0.5172 & 0.3725 \\
\hline Adjusted $R$-squared & 0.5215 & 0.4513 & 0.3643 & 0.3754 & 0.1842 \\
\hline$F$-statistic & 2.7153 & 4.149 & 3.4833 & 3.6472 & 1.9786 \\
\hline Prob (F-statistic) & 0.0000 & 0.0000 & 0.0000 & 0.0000 & 0.0017 \\
\hline
\end{tabular}

The $t$-test statistics are presented in parentheses. $*, * *$, and $* * *$ represent statistical significance on a $10 \%, 5 \%$, and $1 \%$ level, respectively.

TABLE 4: Urban expansion and driving factors in Eastern China.

\begin{tabular}{|c|c|c|c|c|c|}
\hline Item & $\begin{array}{c}\mathrm{U}_{1} \\
(1990-2010)\end{array}$ & $\begin{array}{c}\mathrm{U}_{2} \\
(1990-1995)\end{array}$ & $\begin{array}{c}\mathrm{U}_{3} \\
(1995-2000)\end{array}$ & $\begin{array}{c}\mathrm{U}_{4} \\
(2000-2005)\end{array}$ & $\begin{array}{c}\mathrm{U}_{5} \\
(2005-2010)\end{array}$ \\
\hline Population increment, POPI & $0.2472^{* * *}$ & -0.0036 & 0.1344 & -0.0602 & 0.3077 \\
\hline GDP increment, GDPI & -0.0439 & $0.1435^{* *}$ & -0.1201 & $0.2312^{* * *}$ & 0.0063 \\
\hline Investment increment in capital construction, IICC & -0.0056 & 0.0121 & -0.0039 & 0.0004 & 0.0491 \\
\hline Salary increment per capita, SIPC & -0.0115 & -0.0754 & -0.0001 & 0.0154 & 0.0989 \\
\hline Road increment, RI & $0.2033^{* * *}$ & $0.1545^{* * *}$ & $0.1099^{* *}$ & 0.0981 & -0.0246 \\
\hline Secondary industry product increment, SIPI & 0.1445 & -0.0385 & 0.0067 & $0.1829^{*}$ & $0.1125^{*}$ \\
\hline Tertiary industry product increment, TIPI & -0.0627 & $-0.0808^{*}$ & 0.1184 & $0.2038^{* *}$ & 0.0123 \\
\hline Electricity consumption increment, ECI & $0.1402^{*}$ & -0.0386 & $0.0378^{* * *}$ & $0.0897^{* *}$ & 0.0178 \\
\hline Constant & 0.2472 & 0.0498 & 0.0238 & 0.0058 & 0.0448 \\
\hline Durbin-Watson stat & 2.6245 & 2.2180 & 2.3189 & 2.1241 & 2.0733 \\
\hline$R$-squared & 0.5107 & 0.4951 & 0.4826 & 0.4389 & 0.2895 \\
\hline Adjusted $R$-squared & 0.3794 & 0.2536 & 0.3019 & 0.2490 & 0.0200 \\
\hline$F$-statistic & 3.8905 & 0.0545 & 2.6706 & 2.3109 & 1.0741 \\
\hline $\operatorname{Prob}(F$-statistic) & 0.0000 & 2.0503 & 0.0012 & 0.0048 & 0.3994 \\
\hline
\end{tabular}

The $t$-test statistics are presented in parentheses. $*, * *$, and $* * *$ represent statistical significance on a $10 \%, 5 \%$, and $1 \%$ level, respectively.

constrained by the control policy. However, for Western China, economic development was the first priority. The urban expansion of most cities in Western China was the most rapid between 2005 and 2010.

During period $U_{5}$ (2005-2010), Changchun, Changsha, Kunming, Nanchang, Urumqi, and Xi'an expanded the most dramatically. The urban expansion rate of Kunming was $22.9 \%$ and that of Urumqi was $18.52 \%$. The urban expansion of the other twenty-five cities was slower in period $U_{5}$ than in period $\mathrm{U}_{4}$.

City-level built-up areas sometimes increase abruptly due to the effect of a large built-up area project. For example, the urban land of Beijing expanded by $20.15 \%, 2.31 \%, 142.21 \%$, and $14.21 \%$ during the four time periods (periods $\mathrm{U}_{2-5}$ ). The urban expansion of Shanghai was also uneven across the four periods (56\%, 41.03\%, 49.09\%, and 139.85\%). Relatively speaking, the urban expansion of Guangzhou increased evenly by $42.31 \%, 66.41 \%, 70.53 \%$, and $70.44 \%$ in the four periods, respectively.

3.2. The Driving Factors of National-Scale Urban Expansion. Many studies argue that economic growth stimulates urban expansion in China through a positive correlation between the two indicators $[15,25]$. In the Pearl River Delta, largescale investments in industrial development played the major role in urban land conversion [1]. Urban land expansion is not 
TABLE 5: Urban expansion and driving factors in Middle China.

\begin{tabular}{|c|c|c|c|c|c|}
\hline Item & $\begin{array}{c}\mathrm{U}_{1} \\
(1990-2010)\end{array}$ & $\begin{array}{c}\mathrm{U}_{2} \\
(1990-1995)\end{array}$ & $\begin{array}{c}\mathrm{U}_{3} \\
(1995-2000)\end{array}$ & $\begin{array}{c}\mathrm{U}_{4} \\
(2000-2005)\end{array}$ & $\begin{array}{c}\mathrm{U}_{5} \\
(2005-2010)\end{array}$ \\
\hline Population increment, POPI & 0.0033 & 0.1957 & 0.0351 & $0.5964^{* *}$ & 0.5050 \\
\hline GDP increment, GDPI & $0.1454^{*}$ & $0.0853^{* *}$ & $0.6265^{* * *}$ & $0.1962^{* *}$ & $0.7574^{* * *}$ \\
\hline Investment increment in capital construction, IICC & -0.0260 & 0.0098 & 0.0637 & 0.0341 & 0.0411 \\
\hline Salary increment per capita, SIPC & 0.0299 & $0.1114^{* *}$ & -0.0011 & 0.5759 & -0.3751 \\
\hline Road increment, RI & -0.0385 & -0.0150 & -0.0608 & -0.0065 & -0.3041 \\
\hline Secondary industry product increment, SIPI & $0.1287^{* *}$ & 0.0203 & $0.2551^{* *}$ & 0.0156 & $0.1206^{* *}$ \\
\hline Tertiary industry product increment, TIPI & 0.0060 & -0.0154 & $0.2786^{*}$ & $0.0368^{* * *}$ & $0.2661^{* * *}$ \\
\hline Electricity consumption increment, ECI & -0.0362 & 0.0668 & -0.0623 & $0.1034^{* * *}$ & $0.1673^{* * *}$ \\
\hline Constant & 0.0895 & 0.0785 & 0.0323 & 0.0287 & 0.4017 \\
\hline Durbin-Watson stat & 2.0513 & 2.5574 & 2.7548 & 2.3350 & 2.7245 \\
\hline R-squared & 0.2281 & 0.9928 & 0.3597 & 0.6839 & 0.8315 \\
\hline Adjusted R-squared & 0.0774 & 0.9877 & 0.0064 & 0.5307 & 0.5618 \\
\hline F-statistic & 1.5140 & 191.6067 & 1.0180 & 4.4631 & 3.0836 \\
\hline Prob (F-statistic) & 0.1146 & 0.0000 & 0.4670 & 0.0001 & 0.0380 \\
\hline
\end{tabular}

The $t$-test statistics are presented in parentheses. $*, * *$, and $* * *$ represent statistical significance on a $10 \%, 5 \%$, and $1 \%$ level, respectively.

TABLE 6: Urban expansion and driving factors in Western China.

\begin{tabular}{|c|c|c|c|c|c|}
\hline Item & $\begin{array}{c}\mathrm{U}_{1} \\
(1990-2010)\end{array}$ & $\begin{array}{c}\mathrm{U}_{2} \\
(1990-1995)\end{array}$ & $\begin{array}{c}\mathrm{U}_{3} \\
(1995-2000)\end{array}$ & $\begin{array}{c}\mathrm{U}_{4} \\
(2000-2005)\end{array}$ & $\begin{array}{c}\mathrm{U}_{5} \\
(2005-2010)\end{array}$ \\
\hline Population increment, POPI & 0.1707 & $0.7961^{* * *}$ & 0.1228 & $0.2537^{* *}$ & -0.1804 \\
\hline GDP increment, GDPI & $0.0902^{* * *}$ & -0.4907 & $2.9207^{* * *}$ & -0.2369 & $0.1660^{* * *}$ \\
\hline Investment increment in capital construction, IICC & -0.0041 & -0.0015 & 0.0155 & 0.0208 & 0.0696 \\
\hline Salary increment per capita, SIPC & 0.0142 & 0.1159 & 0.0236 & -0.0338 & $0.1406^{* *}$ \\
\hline Road increment, RI & 0.0053 & 0.0123 & 0.0437 & $0.1559^{*}$ & $0.0835^{* *}$ \\
\hline Secondary industry product increment, SIPI & -0.0649 & $0.2180^{* *}$ & $1.5654^{* * *}$ & -0.0884 & 0.1529 \\
\hline Tertiary industry product increment, TIPI & -0.0059 & $0.3083^{*}$ & $1.2645^{* * *}$ & 0.1103 & -0.0566 \\
\hline Electricity consumption increment, ECI & $0.0289^{* * *}$ & -0.0025 & 0.0197 & 0.0930 & $0.0455^{*}$ \\
\hline Constant & 0.0670 & -0.0088 & 0.0496 & 0.1096 & 0.0268 \\
\hline Durbin-Watson stat & 1.9862 & 1.6960 & 2.0995 & 2.7043 & 2.6269 \\
\hline$R$-squared & 0.2081 & 0.4667 & 0.3405 & 0.6997 & 0.6364 \\
\hline Adjusted $R$-squared & 0.0689 & 0.3374 & 0.2178 & 0.5186 & 0.4209 \\
\hline$F$-statistic & 1.4947 & 3.6092 & 2.7747 & 0.4566 & 2.9531 \\
\hline $\operatorname{Prob}(F$-statistic) & 0.1189 & 0.0041 & 0.0144 & 0.8773 & 0.0064 \\
\hline
\end{tabular}

The $t$-test statistics are presented in parentheses. $*, * *$, and $* * *$ represent statistical significance on a $10 \%, 5 \%$, and $1 \%$ level, respectively.

only the consequences of economic growth, but also drivers of such growth [22]. We studied the relationship between urban expansion and eight social and economic indicators.

For period $U_{1}$ (1991-2010), national-scale urban expansion was positively correlated with the four driving factors (POPI, SIPC, SIPI, and RI). The regression coefficient between urban expansion and POPI was 0.2038 , indicating the highest impact on urban expansion. Table 3 summarizes the model for urban expansion and the driving factors that were included. The relationship between urban expansion and the three driving factors (SIPC, SIPI, and RI) was statistically significant at a 5\% level while the relationship between urban expansion and POPI was statistically significantly at a $1 \%$ level (Table 3). Salary increase per capita (SIPC) motivates farmers to migrate to the cities. Increases in secondary industrial production (SIPI) can impact urban expansion. For period $\mathrm{U}_{1}$, population increment (POPI) and salary increase per capita (SIPC) were the dominant driving factors for urban expansion, followed by SIPI and RI that were the other major driving factors (Table 3 ).

Urban expansion had different characteristics in the different time periods. In period $U_{2}$ (1991-1995), urban expansion was positively correlated with population growth (POPI), economic development (GDPI), and electricity consumption increment (ECI) at $1 \%$ level (Table 3). Urban expansion was significantly positively correlated with tertiary industry product increment (TIPI) at $5 \%$ level. The regression coefficient between urban expansion and POPI was the 
highest. Urban expansion was also strongly influenced by economic development and electricity consumption increment (GDPI and ECI). In period $U_{3}$ (1995-2000), urban expansion was positively correlated with the three driving factors of GDPI, POPI, and ECI (Table 3). The regression coefficient with GDPI was the highest. For period $\mathrm{U}_{4}(2000-$ 2005), urban expansion was positively correlated with four driving factors: SIPI, RI, IICC, and ECI (Table 3). The regression coefficient with SIPI was the highest. For this period, SIPI was the greatest driving factor for urban expansion. RI and IICC were also major driving factors for urban expansion. In period $U_{5}(2005-2010)$, urban expansion was positively correlated with IICC, POPI, and SIPI. IICC had the highest regression coefficient and was the most important driving factor of urban expansion. POPI stimulated urban expansion at a less high level.

From above analysis, the urban expansion was correlated with the social and economic factors. However, the driving factors were dramatically different for different periods. For the periods $U_{2}$ (1991-1995) and $U_{3}(2000-2005)$, POPI and GDPI were the primary factors. For the period $\mathrm{U}_{3}$ (19952000), the secondary industry and road increment became the dominant driving factors while investment increment in capital construction and electricity consumption became the primary driving factors for period $\mathrm{U}_{5}(2005-2010)$.

3.3. The Urban Expansion of Eastern, Middle, and Western China and Its Driving Factors. To compare the differences between the three regions, we studied the relationships between urban expansion and its driving factors in Eastern, Middle, and Western China.

In Eastern China, urban expansion was positively correlated with POPI, RI, and ECI during period $\mathrm{U}_{1}$ (Table 4). Population increment (POPI) was the strongest stimulant of urban expansion. Road increment was the secondly most important driving factor for urban expansion. In period $U_{2}$, urban expansion in Eastern China was positively correlated with two driving factors (RI and GDPI) (Table 4). The regression coefficient was the highest with RI (0.1545). For this period, RI was the dominant driving factor for urban expansion. GDPI also stimulated urban expansion. In period $\mathrm{U}_{3}$, the urban expansion of Eastern China was correlated positively with the two driving factors (ECI and RI) (Table 4). The regression coefficient with ECI was the highest (0.0378). For this period, ECI was the major driving factor for urban expansion. For period $\mathrm{U}_{4}$, urban expansion in Eastern China was correlated positively with four driving factors (GDPI, ECI, TIPI, and SIPI). Urban expansion was most highly correlated with GDPI ( 0.2312 , statistically significant at a $1 \%$ level). For this period, GDPI became the dominant driving factor. ECI and TIPI also stimulated urban expansion during this time. For period $U_{5}$, urban expansion of Eastern China was correlated positively with SIPI (statistically significant at a $10 \%$ level). Urban expansion was most strongly correlated with secondary industry increment. For this period, secondary industry was the most important driving factor for urban expansion. For Eastern China, POPI and RI were the dominant factors for the 20 years. However, RI was the dominant driving factor during period $\mathrm{U}_{2}$. For the period
$\mathrm{U}_{3}$, ECI was the major driving factor. GDPI was the major driving factor for the period $\mathrm{U}_{4}$. The secondary industry was the major driving factor of urban expansion for the period $U_{5}$. In Eastern China, the correlation between urban expansion and IICC cannot pass the significance test.

In Middle China, urban expansion was positively correlated with SIPI and GDPI during period $U_{1}$ (Table 5). The regression coefficient with SIPI was 0.1287 (statistically significant at a $5 \%$ level). For the four periods $\left(\mathrm{U}_{2}, \mathrm{U}_{3}, \mathrm{U}_{4}\right.$, and $\mathrm{U}_{5}$ ), urban expansion was positively correlated with GDPI, based on the panel data analysis (Table 5). Urban expansion was most strongly correlated with SIPI in period $\mathrm{U}_{2}$, GDPI in period $\mathrm{U}_{3}$, TIPI in period $\mathrm{U}_{4}$, and GDPI in period $\mathrm{U}_{5}$. In period $\mathrm{U}_{2}$, SIPI and GDPI were the major driving factors for urban expansion. The secondary industry and economic development stimulated urban expansion in Middle China. For period $U_{3}$, urban expansion was correlated positively with GDPI, SIPI, and TIPI. In period $\mathrm{U}_{4}$, urban expansion was correlated positively with TIPI, ECI, POPI, and GDPI. In this period, tertiary industry stimulated urban expansion. Finally, in period $\mathrm{U}_{5}$, urban expansion had the highest correlation with GDPI. It also exhibited positive correlations with TIPI and ECI. For Middle China, GDPI was the most important driving factor for urban expansion in periods $\mathrm{U}_{3}$ and $\mathrm{U}_{5}$. SIPC and IICC were the most important driving factors of urban expansion for periods $\mathrm{U}_{2}$ and $\mathrm{U}_{4}$. In Middle China, the correlation between urban expansion and IICC cannot pass the significance test. For the twenty years, secondary industry and economic development were the most important factors of urban expansion.

In Western China, urban expansion was correlated positively with GDPI and ECI in period $\mathrm{U}_{1}$ (statistically significant at a $1 \%$ level) (Table 6). The regression coefficient between urban expansion and GDPI was 0.0902. GDPI had the highest correlations with urban expansion. Over the twenty-year study period, economic development stimulated urban expansion in Western China. Moreover, electricity consumption had stimulated urban expansion. In period $\mathrm{U}_{2}$, urban expansion was positively correlated with POPI (statistically significant at a $1 \%$ level), SIPI (statistically significant at a $5 \%$ level), and TIPI (statistically significant at a 10\% level) (Table 6). It exhibited the highest correlation with population growth. For period $U_{3}$, urban expansion was significantly positively correlated with GDPI, SIPI, and TIPI (Table 6). In period $\mathrm{U}_{4}$, urban expansion was positively correlated with POPI (statistically significant at a 5\% level) (Table 6). In period $\mathrm{U}_{5}$, urban expansion was significantly positively correlated with GDPI (statistically significant at a 1\% level). It exhibited the highest correlation with GDPI. SIPI and RI were correlated with urban expansion at 5\% level. ECI was correlated with urban expansion at a 10\% level. For Western China, economic development and population growth had stimulated the urban expansion. Economic development (GDPI) was the major driving factor of urban expansion for the period of $\mathrm{U}_{1}, \mathrm{U}_{3}$, and $\mathrm{U}_{5}$. Population growth (POPI) was the major driving factor for urban expansion during two of the studied five-year periods $\left(\mathrm{U}_{2}\right.$ and $\left.\mathrm{U}_{4}\right)$. But the correlation between urban expansion and IICC cannot pass the significance test. 


\section{Discussion and Conclusion}

Social and economic development has stimulated urban expansion [15, 26, 27]. Moreover, urbanization does have causal effect on economic growth, both within the city and with spillover effect to the region [22]. In this paper, statistical data on land use are integrated with socioeconomic data to develop statistical models of urban expansion. We study the relationship between urban expansion and its driving factors through panel data analysis.

Economic development will attract more rural people to immigrate the cities. At the same time, it will encourage the urban expansion. Economic growth clearly has a major effect on urban expansion. Economic development is the most significant and fundamental driving factors [25]. Economic growth has more impact on urban expansion than population growth and even urban environmental improvement. However, our studies indicate its impact on urban expansion differs in the different regions of China.

For Eastern China, population growth and road construction have become the major factors driving urban expansion. These results highlight the importance of population growth and road construction for urban expansion. For Middle China, secondary industry and economic development became the major driving factors of urban expansion during the twenty-year study period. In the period, the rapid development of secondary industry stimulated urban expansion in Middle China. However, in different periods, the factors of economic development also became major driving factors. For Western China, economic growth was the major driving factor for urban expansion during the twentyyear study period. For different periods, population growth and investment in capital construction and road construction also became major driving factors. Rapid economic growth has resulted in increased demand for urban land. Under the policies aimed at the rapid development of Western China, the rapid economic development of this region has stimulated urban expansion.

Our results have significant policy implications for China, revealing the differences in urban expansion patterns among the three regions. For each of the three regions, there are differences in the major driving factors for urban expansion. At the macrocontrol level of the central government, different policies should be implemented to adjust urban expansion in the different regions. Now the central government implements neo-urbanization policy and encourages the farmers to immigrate into the cities and townships. For Eastern China, population growth and road construction had encouraged the urbanization process. For Middle China, the manufacture industry had more impact on the urbanization process. But for Western China, economic development still impacted the urbanization process. With the economic development and industrial adjustment, the manufacture will immigrate to Middle China and Western China. Therefore, the industrial migration into the Middle and Western China will encourage their urbanization process. However, the population immigration from Middle and Western China to Eastern China will accelerate the urbanization process in Eastern China. At the same time, road construction will accelerate the urbanization process too. The tertiary industry development had no apparent impact on urban expansion. With the social and economic development, the tertiary industry will have more impact on the urbanization process. For the three regions, Eastern China is more developed than Middle China. Middle China is more developed than Western China. For the different regions, their urbanization processes and driving factors are different. The central government should implement different policies to speed up the urbanization process.

\section{Competing Interests}

The authors declare that they have no competing interests.

\section{Acknowledgments}

This research was funded by the National Basic Research Program of China (Grant 2015CB953602).

\section{References}

[1] K. C. Seto and R. K. Kaufmann, "Modeling the drivers of urban land use change in the Pearl River Delta, China: integrating remote sensing with socioeconomic data," Land Economics, vol. 79, no. 1, pp. 106-121, 2003.

[2] K. C. Seto, R. K. Kaufmann, and C. E. Woodcock, "Landsat reveals China's farmland reserves, but they're vanishing fast," Nature, vol. 406, no. 6792, p. 121, 2000.

[3] K. C. Seto, C. E. Woodcock, C. Song, X. Huang, J. Lu, and R. K. Kaufmann, "Monitoring land-use change in the Pearl River Delta using Landsat TM," International Journal of Remote Sensing, vol. 23, no. 10, pp. 1985-2004, 2002.

[4] B. Güneralp and K. C. Seto, "Environmental impacts of urban growth from an integrated dynamic perspective: a case study of Shenzhen, South China," Global Environmental Change, vol. 18, no. 4, pp. 720-735, 2008.

[5] G. J. Tian, J. Y. Liu, and Z. X. Zhang, "Urban functional structure characteristics and transformation in China," Cities, vol. 19, no. 4, pp. 243-248, 2002.

[6] G. J. Tian, J. Y. Liu, Y. C. Xie, Z. F. Yang, D. F. Zhuang, and Z. $\mathrm{Niu}$, "Analysis of spatio-temporal dynamic pattern and driving forces of urban land in China in 1990s using TM images and GIS," Cities, vol. 22, no. 6, pp. 400-410, 2005.

[7] G. Tian, Z. F. Yang, and Y. Q. Zhang, “The spatio-temporal dynamic pattern of rural residential land in China in the 1990s using Landsat TM images and GIS," Environmental Management, vol. 40, no. 5, pp. 803-813, 2007.

[8] G. J. Tian, Z. F. Yang, and Y. C. Xie, “Detecting spatiotemporal dynamic landscape patterns using remote sensing and the lacunarity index: a case study of Haikou City, China," Environment and Planning B: Planning and Design, vol. 34, no. 3, pp. 556-569, 2007.

[9] P. M. Vitousek, H. A. Mooney, J. Lubchenco, and J. M. Melillo, "Human domination of earth's ecosystems," Science, vol. 277, no. 5325, pp. 494-499, 1997.

[10] M. H. Tan, X. B. Li, and C. H. Lü, "Urban land expansion and arable land loss of the major cities in China in the 1990s," Science in China, Series D: Earth Sciences, vol. 48, no. 9, pp. 1492-1500, 2005. 
[11] D. Potere and A. Schneider, "A critical look at representations of urban areas in global maps," GeoJournal, vol. 69, no. 1-2, pp. 55-80, 2007.

[12] National Statistics Bureau, China Statistics Yearbook 1979, China Statistics Press, Beijing, China, 1979.

[13] National Statistics Bureau, China Statistics Yearbook 2011, China Statistics Press, Beijing, China, 2011.

[14] P. H. Verburg, J. R. Ritsema van Eck, T. C. M. de Nijs, M. J. Dijst, and P. Schot, "Determinants of land-use change patterns in the Netherlands," Environment and Planning B: Planning and Design, vol. 31, no. 1, pp. 125-150, 2004.

[15] J. K. Huang, L. F. Zhu, and X. Z. Deng, "The regional difference and driving forces of the urban expansion in China," Science China Earth Sciences, vol. 37, no. 9, pp. 1235-1241, 2007.

[16] C. He, N. Okada, Q. Zhang, P. Shi, and J. Li, "Modelling dynamic urban expansion processes incorporating a potential model with cellular automata," Landscape and Urban Planning, vol. 86, no. 1, pp. 79-91, 2008.

[17] X. Li and X. Liu, "Defining agents' behaviors to simulate complex residential development using multicriteria evaluation," Journal of Environmental Management, vol. 85, no. 4, pp. 10631075, 2007.

[18] F. L. Fan, Y. P. Wang, M. H. Qiu, and Z. S. Wang, "Evaluating the temporal and spatial urban expansion patterns of Guangzhou from 1979 to 2003 by remote sensing and GIS methods," International Journal of Geographical Information Science, vol. 23, no. 11, pp. 1371-1388, 2009.

[19] J.-Z. Gong, Y.-S. Liu, B.-C. Xia, and G.-W. Zhao, "Urban ecological security assessment and forecasting, based on a cellular automata model: a case study of Guangzhou, China," Ecological Modelling, vol. 220, no. 24, pp. 3612-3620, 2009.

[20] X. Li, "Embedding sustainable development strategies in agentbased models for use as a planning tool," International Journal of Geographical Information Science, vol. 22, no. 1, pp. 21-45, 2008.

[21] J. Wang, "Spatial-panel econometric analysis on the relationship between regional regional socio-economic development and construction land use in China," China Land Sciences, vol. 27, no. 8, pp. 52-58, 2013.

[22] X. Bai, J. Chen, and P. Shi, "Landscape urbanization and economic growth in China: positive feedbacks and sustainability dilemmas," Environmental Science and Technology, vol. 46, no. 1, pp. 132-139, 2012.

[23] G. C. S. Lin, "Reproducing spaces of Chinese urbanisation: new city-based and land-centred urban transformation," Urban Studies, vol. 44, no. 9, pp. 1827-1855, 2007.

[24] H. H. Fan and L. Y. Zhang, Eviews Statistics Analysis and Applications, Machinery Industry Press, Beijing, China, 2009.

[25] M. H. Tan, X. B. Li, and C. H. Lü, "An analysis of driving forces of urban land expansion in China," Economic Geography, vol. 23, no. 5, pp. 635-639, 2003 (Chinese).

[26] G. J. Tian, J. Jiang, Z. F. Yang, and Y. Q. Zhang, “The urban growth, size distribution and spatio-temporal dynamic pattern of the Yangtze River Delta megalopolitan region, China," Ecological Modelling, vol. 222, no. 3, pp. 865-878, 2011.

[27] G. Tian, Y. Ouyang, Q. Quan, and J. Wu, "Simulating spatiotemporal dynamics of urbanization with multi-agent systems-A case study of the phoenix metropolitan region, USA," Ecological Modelling, vol. 222, no. 5, pp. 1129-1138, 2011. 

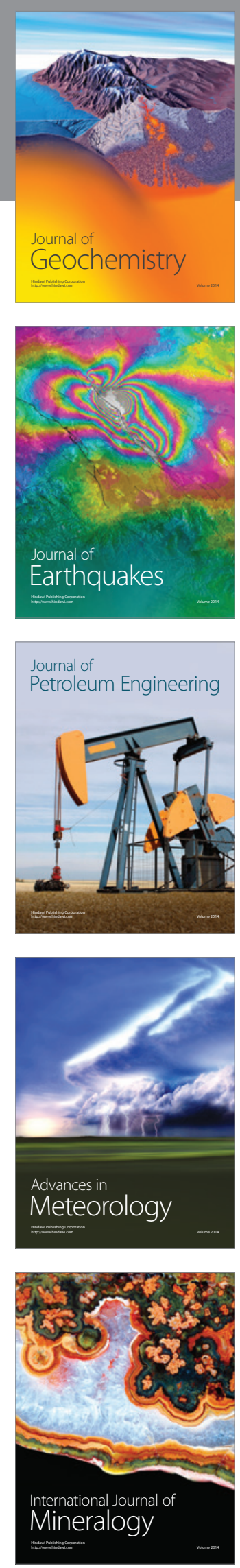
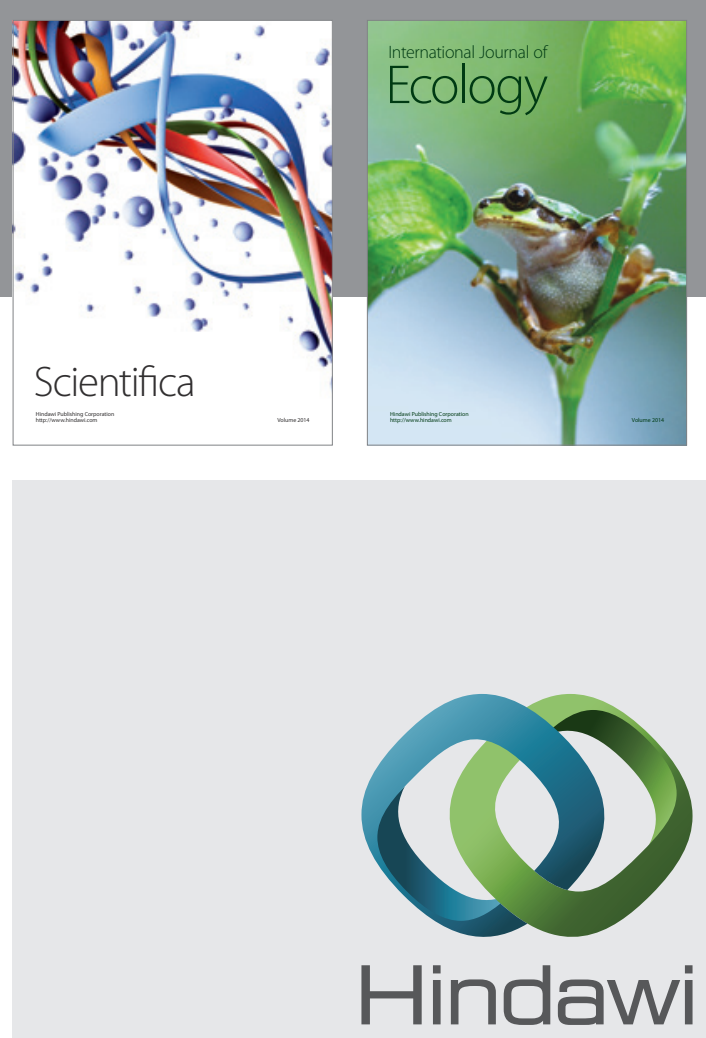

Submit your manuscripts at

http://www.hindawi.com
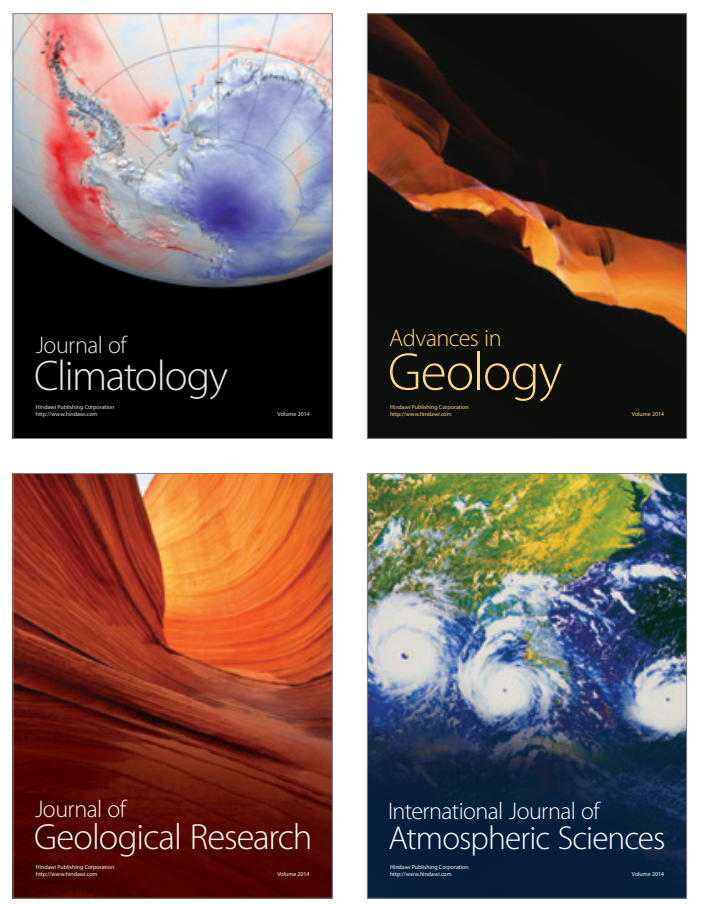

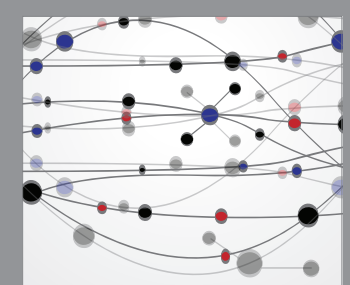

The Scientific

\section{World Journal}
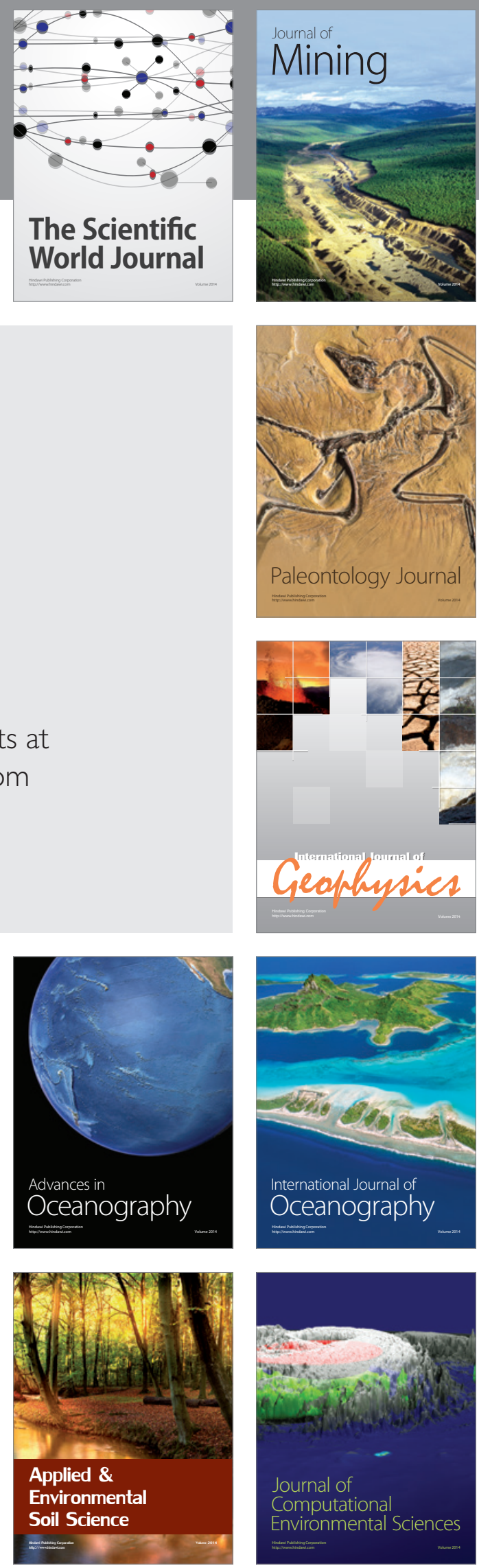